Article

\title{
Ag-ZnO Nanocomposites Are Used for SERS Substrates and Promote the Coupling Reaction of PATP
}

\author{
Liping Ma ${ }^{1}$, Qijia Zhang ${ }^{1}$, Jia Li ${ }^{2}$, Xuemei Lu ${ }^{2}$, Ce Gao ${ }^{1}$, Peng Song ${ }^{2, * \mathbb{D}}$ and Lixin Xia ${ }^{1,3, *}$ \\ 1 College of Chemistry, Liaoning University, Shenyang 110036, China; wksy@lnu.edu.cn (L.M.); \\ zqj13940305120@163.com (Q.Z.); gaoce18802427994@163.com (C.G.) \\ 2 College of Physics, Liaoning University, Shenyang 110036, China; lijia@lnu.edu.cn (J.L.); \\ luxuemei@lnu.edu.cn (X.L.) \\ 3 Yingkou Institute of Technology, Yingkou 115014, China \\ * Correspondence: songpeng@lnu.edu.cn (P.S.); lixinxia@lnu.edu.cn (L.X.); Tel.: +86-246-2202-258 (L.X.)
}

Citation: Ma, L.; Zhang, Q.; Li, J.; Lu, X.; Gao, C.; Song, P.; Xia, L. Ag-ZnO Nanocomposites Are Used for SERS Substrates and Promote the Coupling Reaction of PATP. Materials 2021, 14, 922. https://doi.org/10.3390/ ma14040922

Academic Editor: Andrea Sorrentino Received: 31 December 2020

Accepted: 8 February 2021

Published: 15 February 2021

Publisher's Note: MDPI stays neutral with regard to jurisdictional claims in published maps and institutional affiliations.

Copyright: (c) 2021 by the authors. Licensee MDPI, Basel, Switzerland. This article is an open access article distributed under the terms and conditions of the Creative Commons Attribution (CC BY) license (https:// creativecommons.org/licenses/by/ $4.0 /)$.

\begin{abstract}
Noble metal-semiconductor nanocomposites have received extensive attention in Surface Enhanced Raman Scattering (SERS) due to their unique properties. In this paper, the Ag- $\mathrm{ZnO}$ nanocomposites are prepared by hydrothermal growth and simple chemical reduction immersion. The synthesized nanocomposite material simultaneously integrates the individual enhancement effects of the two materials in the SERS, such as the electromagnetic enhancement of silver nanoparticles and the chemical enhancement of $\mathrm{ZnO}$ semiconductor materials. Using this substrate, Rhodamine 6G molecules with a concentration as low as $10^{-8} \mathrm{M}$ can be detected, and the coupling reaction of PATP can be effectively promoted. The nanocomposite materials prepared by selecting appropriate semiconductor materials and metal materials combined, could be potentially applied, as SERS substrates, in certain catalytic reactions.
\end{abstract}

Keywords: Ag-ZnO; coupling reaction; nanocomposite; PATP; SERS substrate

\section{Introduction}

Surface-enhanced Raman scattering (SERS) refers to the phenomenon that the Raman signals of analytes around the metallic nanostructures is amplified by several orders of magnitude owing to the enhancement of the local electromagnetic field induced by the excitation of the surface plasmon resonance [1-5]. Owing to its high sensitivity, SERS is extensively applied in trace molecular detection, biomolecular analysis, and material characterization, besides other fields [6-8]. The SERS substrate significantly affects the SERS enhancement effect, and a substantial research has been pooled for finding a type of SERS substrate that has a uniform and stable enhancement effect $[9,10]$.

When light is incident on the metal interface, surface plasmons are generated. This phenomenon is considered to be the primary cause for SERS. Therefore, the noble metal structures have been selected as the best material for SERS substrates [11]. Various semiconductor materials have been detected to produce weak SERS activity enhancement factors of $10^{1}-10^{3}$. The enhancement follows from the chemical enhancement caused by the charge transfer [12-14]. Therefore, the combination of semiconductors and metal materials has attracted the attention of researchers, and there have been numerous reports on the application of such composite materials in SERS [15-17].

$\mathrm{ZnO}$ has received special attention, owing to its excellent performance as a multifunctional semiconductor material, in supporting the chemical enhancement of SERS substrates [18,19]. Furthermore, its composite with precious metal nanoparticles as a SERS substrate has also become a research hotspot. Existing research results show that through the combined effects of electromagnetic enhancement and chemical enhancement, noble metal-ZnO composite nanomaterials can be used as viable materials for SERS enhancement substrates [20-26]. Here, we have prepared an Ag-ZnO nanocomposite as a SERS substrate, 
which has excellent reinforcement properties and good uniformity. We have used R6G as the probe molecule to detect the enhancement effect of the composite material as the SERS substrate, and concomitantly, the substrate also has excellent uniformity. Owing to the electron transfer between $\mathrm{Ag}$ and $\mathrm{ZnO}$ and the local surface plasmon effect of the metal surface, the application of the substrate can effectively promote the catalytic coupling reaction that converts PATP to DMAB. The nanocomposite materials, prepared by selecting the appropriate semiconductor materials and metal materials, combined, have the potential worth developing in the application of SERS substrates and certain catalytic reactions.

\section{Experimental}

\subsection{Chemicals}

All the chemicals were purchased from Sinopharm Chemical Reagent Co. Ltd. (Shanghai, China) and applied directly without any treatment. The aqueous solutions involved are freshly prepared from Milli-Q purified water $\left(>18 \mathrm{M} \Omega \mathrm{cm}^{-1}\right)$.

\subsection{Instrumentation}

Scanning electron microscopy (SEM) images were collected on a Hitachi SU8010 field emission scanning electron microscope (Tokyo, Japan) at $10 \mathrm{kV}$. Transmission electron microscope (TEM) and high resolution transmission electron microscopy (HRTEM) images were recorded by using a JEM-2100 ultrahigh-resolution transmission electron microscope (Tokyo, Japan) at $200 \mathrm{kV}$. X-ray photoelectron spectroscopy (XPS) studies were carried out on the thermo scientific ESCALAB 250 instrument (Waltham, MA, USA) using an Al K $\alpha$ monochromated ( $150 \mathrm{w}, 30.0 \mathrm{eV}$ Pass Energy, $500 \mu \mathrm{m}$ Spot Size). X-ray diffraction (XRD) patterns have been recorded on a Bruker D8 ADVANCE (Brooke, Germany) diffractometer by employing $\mathrm{Cu} \mathrm{K} \alpha$ radiation. SERS images were captured using a Renishaw (Renishaw, UK) inVia Reflex confocal Raman system with an excitation wavelength of $532 \mathrm{~nm}$ and a power of $5 \mathrm{~mW}$. The spectral range is $200-1000 \mathrm{~nm}$ and the spectral resolution is $1 \mathrm{~cm}^{-1}$. Spectra were collected by focusing the laser line onto the sample using a $50 \times$ (numerical aperture of 0.75 ) objective, providing a spatial resolution of approximately $1 \mathrm{~mm}$. The data acquisition time was $1 \mathrm{~s}$ for a single accumulation.

\subsection{Preparation of $\mathrm{Ag}-\mathrm{ZnO}$ Nanocomposite}

A uniform zinc oxide nanorod array was prepared by the previous method $[27,28]$. First, zinc acetate was dissolved in a mixed solution of ethanolamine and 2-methoxyethanol, where the concentrations of zinc acetate and ethanolamine are both $0.75 \mathrm{M}$. The mixed solution was heated and stirred for $30 \mathrm{~min}$ at $60{ }^{\circ} \mathrm{C}$ to obtain $\mathrm{ZnO}$ seed solution. Thereafter, the $1 \times 2$ silicon wafer was immersed in the above-mentioned seed solution, and then taken out after $30 \mathrm{~min}$ to dry and then thermally annealed for $10 \mathrm{~min}$ at $300^{\circ} \mathrm{C}$. The annealed silicon wafer was immersed in a mixed solution of $0.1 \mathrm{M}$ zinc nitrate and hexamethylenetetramine, and hydrothermally heated for $2 \mathrm{~h}$ at $95{ }^{\circ} \mathrm{C}$. Finally, the silver nanoparticles were grown on the $\mathrm{ZnO}$ nanorod array by chemical reduction and impregnation. The specific process entailed immersing the $\mathrm{ZnO}$ array substrate in $0.1 \mathrm{M} \mathrm{NaBH}_{4}$ for $5 \mathrm{~s}$, and then immersing it in $0.1 \mathrm{M} \mathrm{AgNO}_{3}$ solution for $5 \mathrm{~s}$. We repeated the process four times, then rinsed the substrate with deionized water and blew it dry with nitrogen.

\section{Results and Discussion}

\subsection{Characterization of $\mathrm{Ag}-\mathrm{ZnO}$ Nanocomposite}

As shown in Figure 1A, the SEM image shows that subsequent to thermal annealing and hydrothermal growth, $\mathrm{ZnO}$ nanorods with a diameter of about $150 \mathrm{~nm}$ are uniformly grown on the silicon wafer. Subsequent to a simple chemical reduction immersion method, the silver nanoparticles with an average diameter of about $25 \mathrm{~nm}$ have been successfully grown on the $\mathrm{ZnO}$ nanorods, as shown in the Figure 1B. Further, Figure 1C,D are the TEM image of $\mathrm{Ag}-\mathrm{ZnO}$ composite material, and it can be clearly seen that the silver nanoparticles are arranged evenly and densely on the $\mathrm{ZnO}$ nanorods (Figure 1D is a partial enlarged view 
of Figure 1C). The HRTEM images of the composite material have been shown in Figure 1E,F, and the lattice spacing of $0.237 \mathrm{~nm}$ corresponds to the (111) plane of the silver nanoparticles. Therefore, it can be proved that the silver nanoparticles have been successfully grown on the $\mathrm{ZnO}$ nanorods. (Figure $1 \mathrm{~F}$ is a partial enlarged view of Figure 1E).
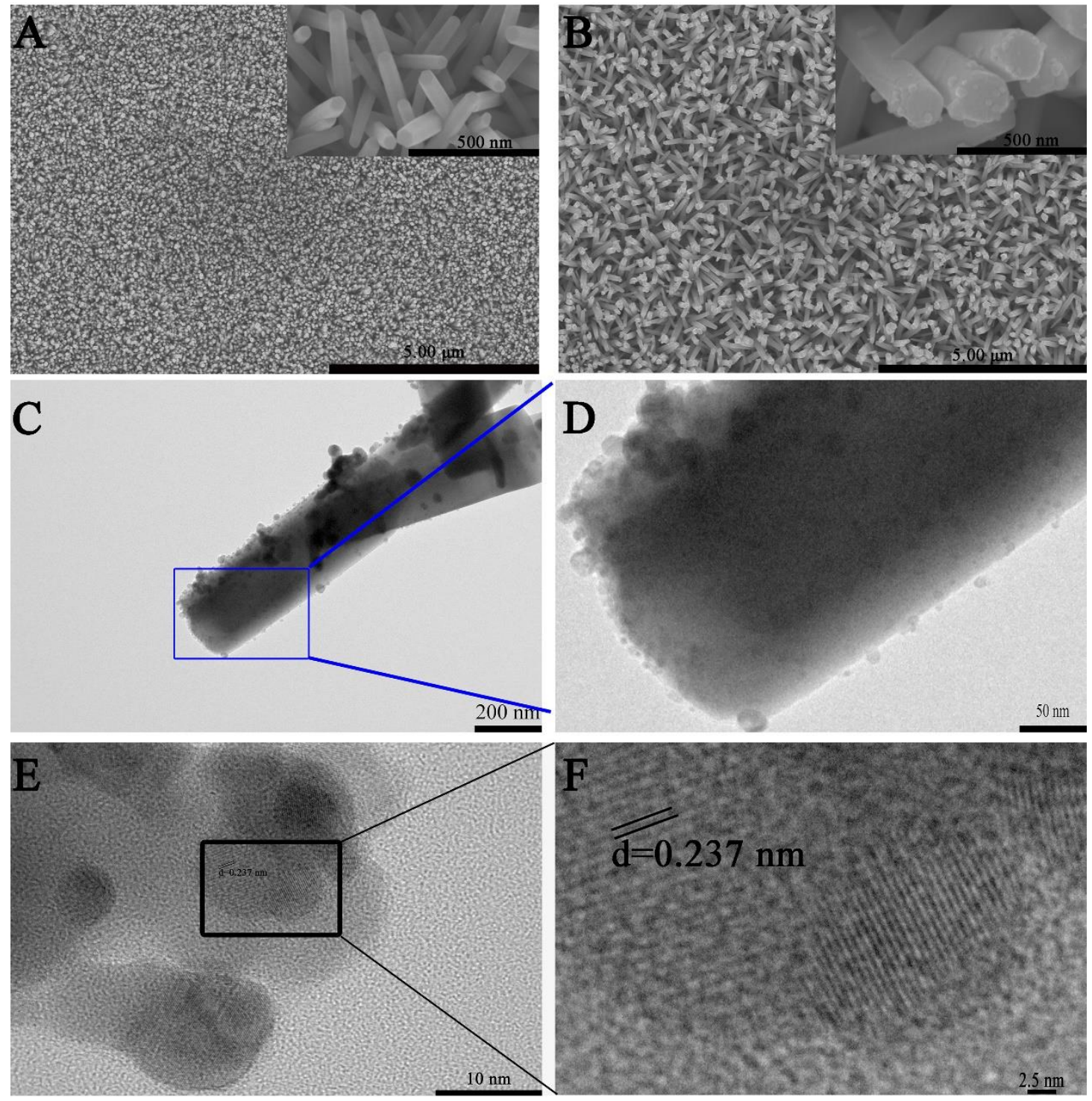

Figure 1. (A) SEM image of the pure $\mathrm{ZnO}$ nanorod and (B) Ag- $\mathrm{ZnO}$ nanorod array; (C) TEM image of the Ag- $\mathrm{ZnO}$ nanorod array and (D) partial enlarged view of (C,E) HRTEM image of the Ag-ZnO nanorod array and (F) partial enlarged view of (E).

Figure 2 shows the XRD pattern of the nanocomposite material. The diffraction patterns have been indexed with Bragg planes (100), (002), (101), (102), (110), (103) and (111), (220) following the comparison with standard pattern, suggesting that both wurtzite $\mathrm{ZnO}$ and metal $\mathrm{Ag}$ exist and confirming the successful preparation of $\mathrm{Ag}-\mathrm{ZnO}$ nanocomposites.

Figure $3 \mathrm{~A}$ shows the XPS spectrum of $\mathrm{Zn} 2 \mathrm{p}$ in the $\mathrm{Ag}-\mathrm{ZnO}$ nanocomposite. It can be seen from the spectrum that it presents two independent symmetrical peaks. The two characteristic peaks with binding energies at 1023 and $1046 \mathrm{eV}$ have been attributable to $\mathrm{Zn}$ $2 p_{3 / 2}$ and $\mathrm{Zn} 2 \mathrm{p}_{1 / 2}$, respectively, indicating that $\mathrm{Zn}$ mainly exists in the form of $\mathrm{Zn}^{2+}$ [29]. Figure 3B shows the XPS spectrum of Ag 3d, where the two characteristic peaks at 367.8 and $373.9 \mathrm{eV}$ have been attributed to $\mathrm{Ag} 3 \mathrm{~d}_{3 / 2}$ and $\mathrm{Ag} 3 \mathrm{~d}_{5 / 2}$, respectively [30,31]. It can be seen that the binding energy of $\mathrm{Ag} 3 \mathrm{~d}$ in the composite material moves to a high field, indicating that the electron transfer has occurred between $\mathrm{Ag}-\mathrm{ZnO}$ ( $\mathrm{BE}$ value of $\mathrm{Ag}^{0}$ and 
$\mathrm{Ag}^{+}$is about 368.2 and $367.2 \mathrm{eV}$, respectively). Since the Fermi energy level of $\mathrm{Ag}$ is higher than $\mathrm{ZnO}$, a Mott Schottky barrier will be formed at the $\mathrm{Ag}-\mathrm{ZnO}$ interface, and the hot electrons will be transferred from $\mathrm{Ag}$ to the conduction band of $\mathrm{ZnO}$ until the Fermi energy levels of both sides are in a straight line. Consequently, the number of hot electrons on the Ag surface decreases.

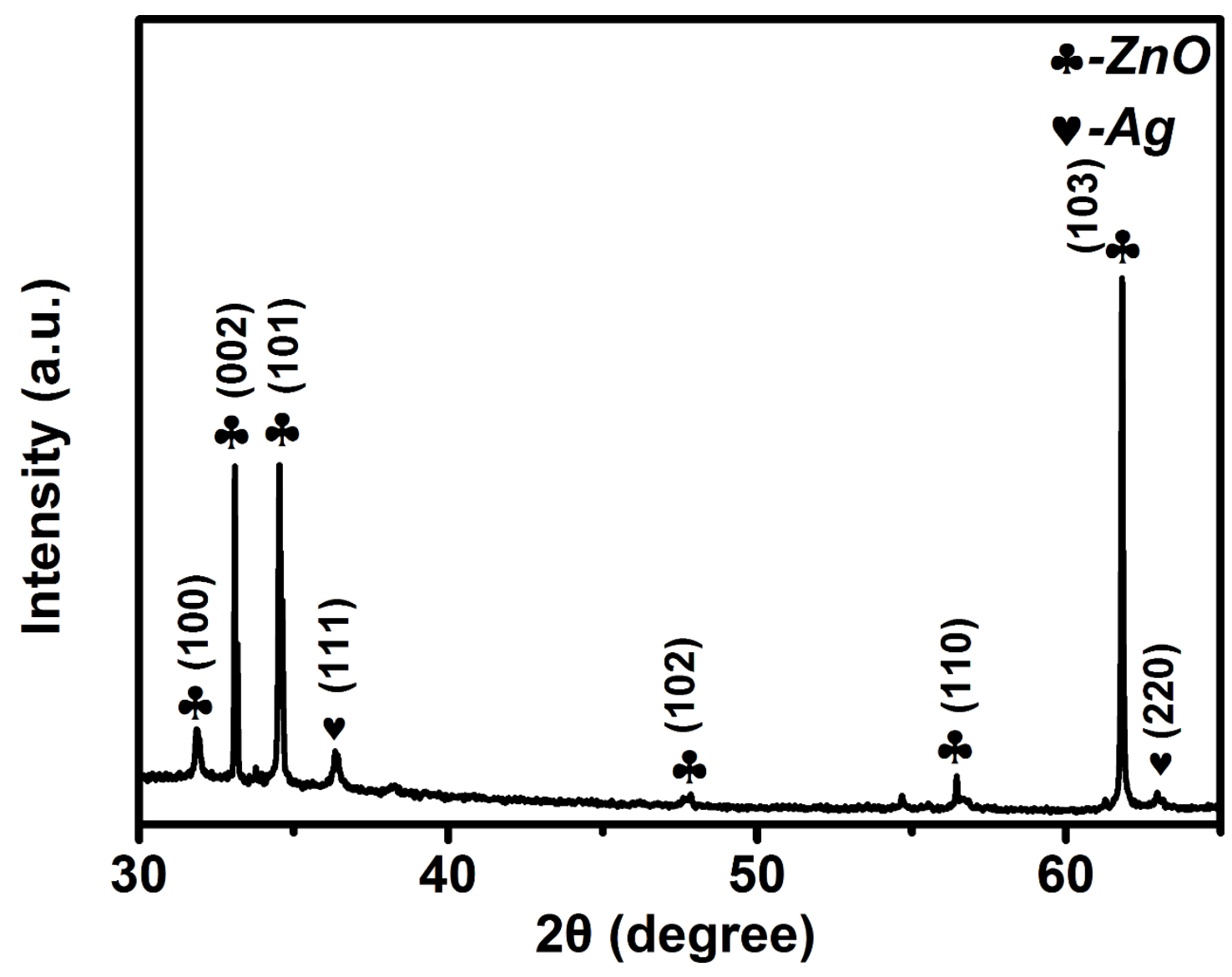

Figure 2. XRD spectra of the $\mathrm{Ag}-\mathrm{ZnO}$ nanorod array.
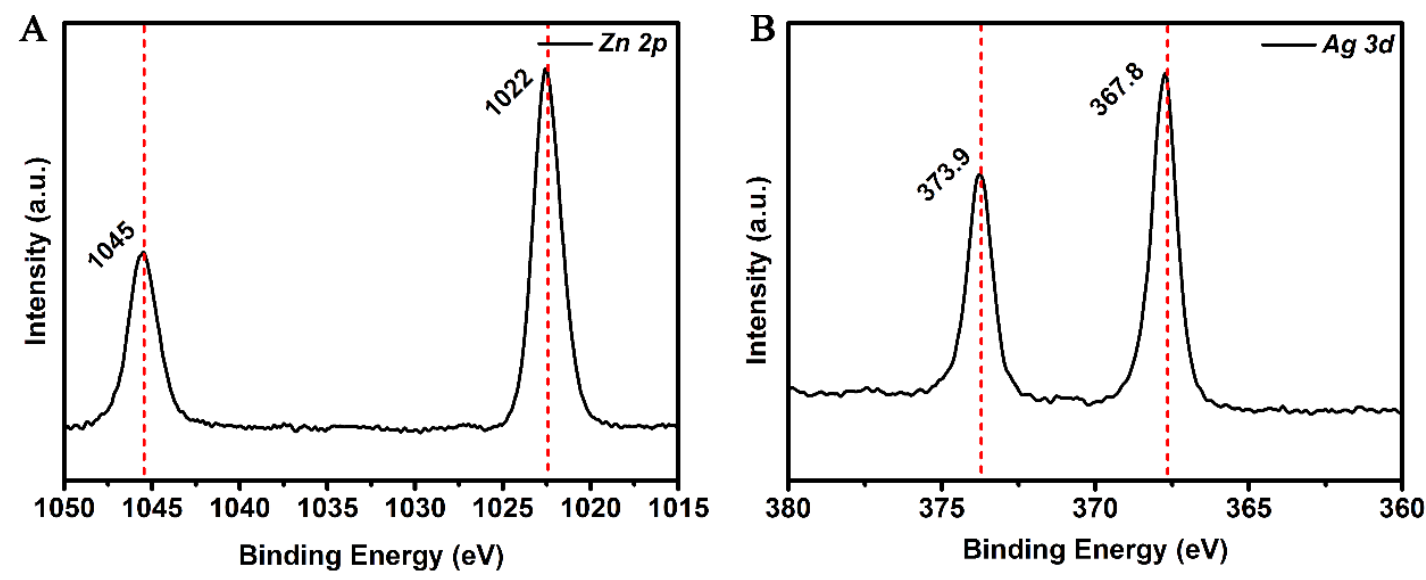

Figure 3. (A)XPS spectra of Zn 2p; (B) Ag 3d.

\section{2. $A g-Z n O$ as the SERS Substrate}

To study the feasibility of $\mathrm{Ag}-\mathrm{ZnO}$ composite nanomaterials as SERS substrates, R6G probe molecules have been used to test their SERS enhancement performance. Figure 4 
shows the Raman spectrum of R6G molecules with concentrations ranging from $10^{-4}$ to $10^{-8} \mathrm{M}$ adsorbed on the $\mathrm{Ag}-\mathrm{ZnO}$ substrate, the peak at $611 \mathrm{~cm}^{-1}$ assigned to $\mathrm{C}-\mathrm{C}-\mathrm{C}$ bond stretching vibration, the peaks at $1309,1365,1509$, the peak of $1647 \mathrm{~cm}^{-1}$ assigned to C-C stretching modes, the peak at $770 \mathrm{~cm}^{-1}$ assigned to the out-of-plane vibration of deformed $\mathrm{C}-\mathrm{H}$ bonds, and the peak at $1573 \mathrm{~cm}^{-1}$ assigned to $\mathrm{C}-\mathrm{O}-\mathrm{C}$ bond stretching vibration. It can be seen that the characteristic Raman peak of R6G molecules can still be observed when the concentration is as low as $10^{-8} \mathrm{M}$.

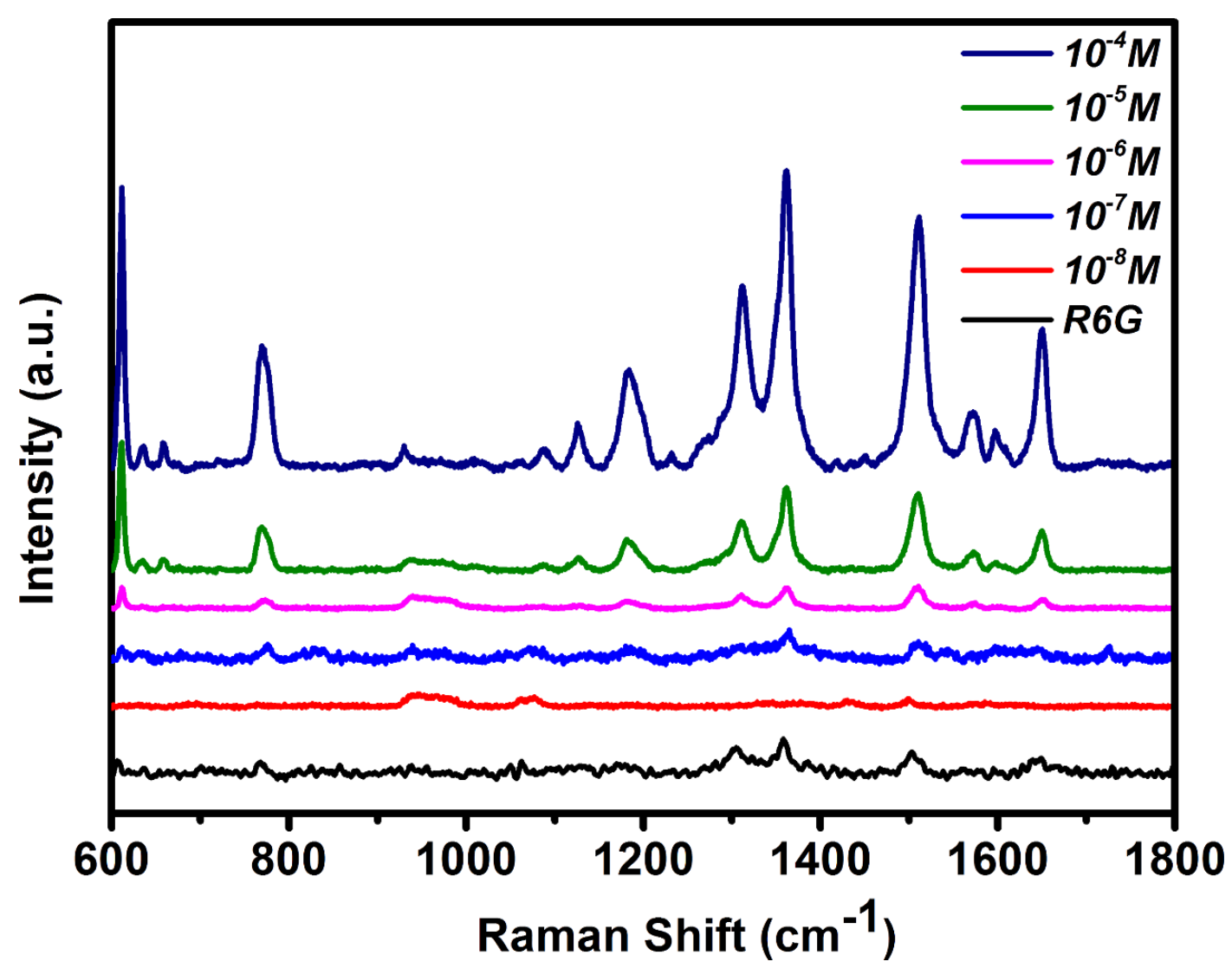

Figure 4. SERS images of $10^{-4}-10^{-8} \mathrm{M}$ R6G adsorbed on the Ag-ZnO nanorod array substrate.

\subsection{Coupling Reaction of PATP on Ag-ZnO Substrate}

Figure $5 \mathrm{~A}$ shows the Raman mapping of $10^{-5} \mathrm{M}$ PATP adsorbed on the Ag- $\mathrm{ZnO}$ substrate, and the three characteristic peaks of 1140,1390 , and $1434 \mathrm{~cm}^{-1}$ belonging to DMAB can be clearly observed, indicating the occurrence of the coupling reaction of PATP molecules adsorbed on $\mathrm{Ag}-\mathrm{ZnO}$ substrate. Table 1 shows the measured frequencies of the Raman bands and their assignments for PATP and DMAB. The coupling reaction of PATP is an oxidation reaction induced by thermal holes [32]. The Fermi level of Ag is higher than that of $\mathrm{ZnO}$, and a Mott Schottky barrier is formed at the $\mathrm{Ag}-\mathrm{ZnO}$ interface. The hot electrons have been transferred from $\mathrm{Ag}$ to the conduction band of $\mathrm{ZnO}$ until the Fermi levels of both sides are at the same level $[26,33]$. The number of hot electrons on the Ag surface decreases, and the hot holes increase. This conclusion has been confirmed by the previous XPS conclusion. Concomitantly, silver nanoparticles absorb light and generate electron-hole pairs through the surface plasmon activity. The thermal pores in the metal can capture electrons from the adsorbed PATP molecule HOMO. The combined effect of the charge transfer and surface plasmon promotes the PATP coupling reaction (Scheme 1). 


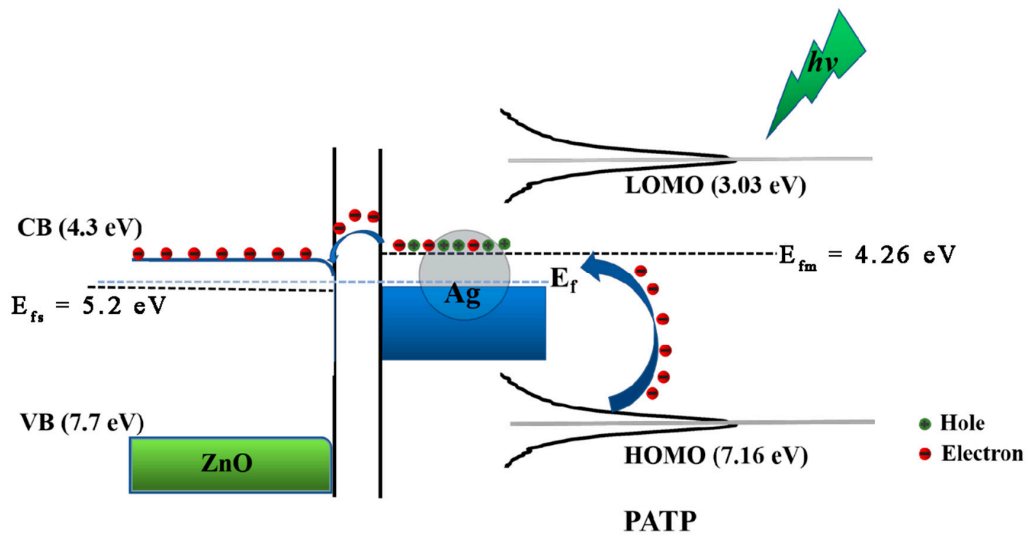

Scheme 1. Schematic diagram of the coupling reaction mechanism of PATP adsorbed on Ag-ZnO substrate.

To eliminate the influence of the supporting substrate on the experimental results, we have used Silicon wafer, ordinary glass, and conductive glass as the support $10^{-5} \mathrm{M}$ PATP as the probe molecule, and obtained Raman spectra under the same experimental conditions (Figure 5B). It can be seen that the PATP coupling reaction occurs on different supports, indicating that the support has no effect on the reaction. A total of 100 samples in a $10 \times 10 \mu \mathrm{m}$ square area on the substrate have been selected for the mapping analysis. As shown in Figure 5C,D, it can be seen that the reaction has a good response effect in the selected area. It shows that the substrate has an excellent uniformity and good Raman enhancement effect.

A
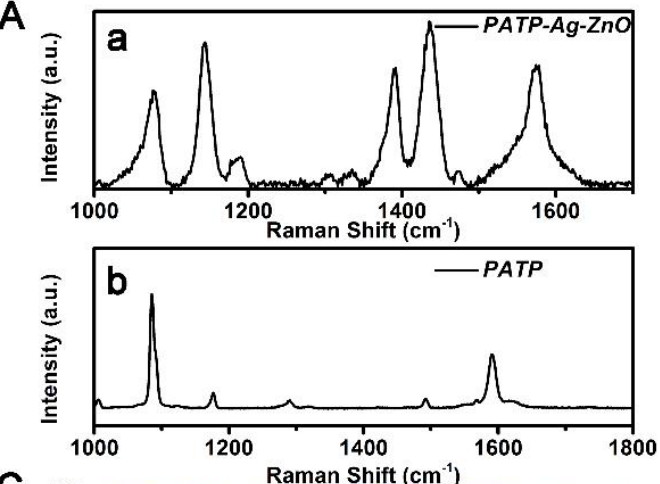

C

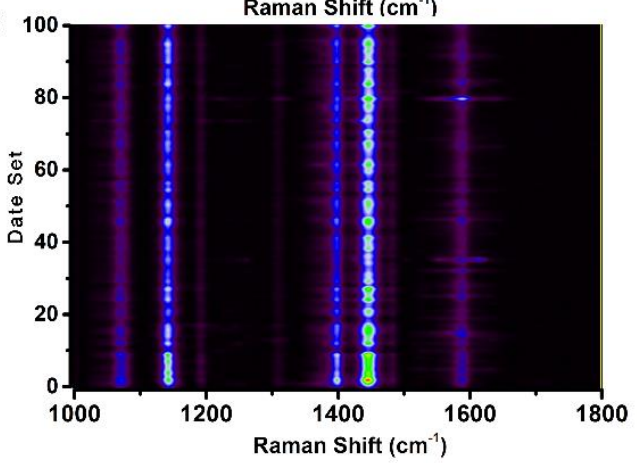

B
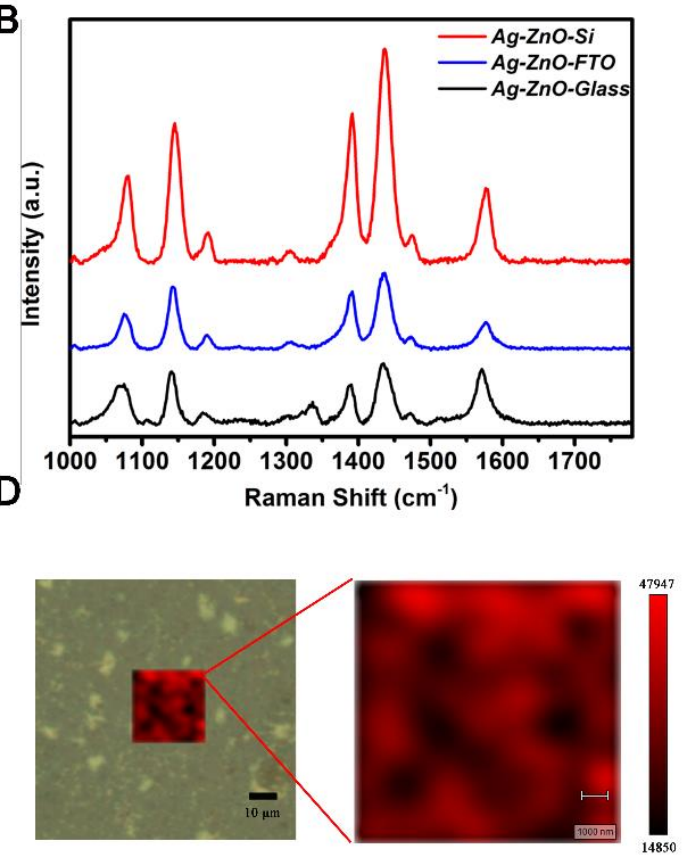

Figure 5. (A) a-SERS spectra of $10^{-5} \mathrm{M}$ PATP on the Ag-ZnO-Si substrate, $b$-SERS spectra of PATP powder; (B) SERS spectra of $10^{-5} \mathrm{M}$ PATP on Ag-ZnO substrate supported by different substrates; (C) Raman mapping images of $10^{-5} \mathrm{M}$ PATP adsorbed on the $\mathrm{Ag}-\mathrm{ZnO}$ nanorod array substrate; (D) Raman intensity distribution map at $1434 \mathrm{~cm}^{-1}$ in the selected range.

Table 1. The measured frequencies of the Raman bands and their assignments for PATP and DMAB.

\begin{tabular}{c|ccc}
\hline \multicolumn{2}{c}{ PATP } & & DMAB \\
\hline Assignment & $\begin{array}{c}\text { Measured } \\
\text { Frequency } \mathbf{( \mathbf { c m } ^ { - 1 } )}\end{array}$ & $\begin{array}{c}\text { Measured } \\
\text { Frequency } \mathbf{( c m}^{-\mathbf{1})}\end{array}$ \\
\hline $\mathrm{N}(\mathrm{CS})+\mathrm{N}(\mathrm{CC})$ & 1087 & $v(\mathrm{CN})+\delta(\mathrm{CH})$ & 1146 \\
$\Delta(\mathrm{CH})$ & 1179 & $v(\mathrm{NN})+v(\mathrm{CC})+\delta(\mathrm{CH})$ & 1390 \\
$\mathrm{~N}(\mathrm{CC})+\Delta(\mathrm{CH})$ & 1289 & $v(\mathrm{NN})+\delta(\mathrm{CH})+v(\mathrm{CC})$ & 1435 \\
$\mathrm{~N}(\mathrm{CC})+\Delta(\mathrm{CH})$ & 1493 & &
\end{tabular}




\section{Conclusions}

To summarize, the Ag- $\mathrm{ZnO}$ nanorod array has been successfully synthesized. When it is used in a SERS substrate, it exhibits an excellent enhancement effect, and the uniformity of the substrate is confirmed with the use of the mapping technology. Since the Fermi level of $\mathrm{Ag}$ is higher than that of $\mathrm{ZnO}$ and the Mott Schottky barrier formed at the Ag$\mathrm{ZnO}$ interface, the electron transfer will occur between $\mathrm{ZnO}-\mathrm{Ag}$ until the Fermi level reaches a certain level. This electron transfer, together with the surface plasma, promotes the coupling reaction of PATP molecules. The nanocomposite material combined with the semiconductor and metal nanoparticles has a great potential advantage as a uniform and stable SERS substrate with a good enhancement effect. Concomitantly, owing to the special properties of the charge transfer between the semiconductor materials and metal nano-particles, it also has certain potential applications in the field of catalysis.

Author Contributions: Conceptualization, L.X. and P.S.; methodology, P.S.; software, X.L., J.L.; validation, L.M., Q.Z. and J.L.; formal analysis, P.S.; investigation, C.G.; resources, L.X. and P.S.; data curation, L.M.; writing-original draft preparation, L.M.; writing—review and editing, Q.Z.; visualization, P.S.; supervision, P.S.; project administration, L.X., P.S.; funding acquisition, L.X., P.S. All authors have read and agreed to the published version of the manuscript.

Funding: This work was supported by the LiaoNing Revitalization Talents Program (Grant No. XLYC1807162), the Liaoning Provincial Department of Education Project (Grant No. LQN202009 and LJC201904), the National Natural Science Foundation of China (Grant No. 21671089 and 11974152), the Shenyang High-level Innovative Talents Program (RC200565).

Informed Consent Statement: Not applicable.

Data Availability Statement: Data is contained within the article.

Conflicts of Interest: The authors declare no conflict of interest.

\section{References}

1. Creighton, J.A.; Blatchford, C.G.; Albrecht, M.G. Plasma resonance enhancement of Raman scattering by pyridine adsorbed on silver or gold sol particles of size comparable to the excitation wavelength. J. Chem. Soc. Faraday Trans. Mol. Chem. Phys. 1979, 75, 790-798. [CrossRef]

2. Ding, S.Y.; Yi, J.; Li, J.F.; Ren, B.; Wu, D.Y.; Panneerselvam, R.; Tian, Z.Q. Nanostructure-based plasmon-enhanced Raman spectroscopy for surface analysis of materials. Nat. Rev. Mater. 2016, 1, 16021. [CrossRef]

3. Langer, J.; Aberasturi, D.J.D.; Aizpurua, J.; Alvarez-Puebla, R.A.; Liz-Marzán, L.M. Present and Future of Surface Enhanced Raman Scattering. ACS Nano 2020, 14, 28-117. [CrossRef] [PubMed]

4. Moskovits, M. Surface-enhanced spectroscopy. Rev. Mod. Phys. 1985, 57, 783-826. [CrossRef]

5. Moskovits, M. Surface roughness and the enhanced intensity of Raman scattering by molecules adsorbed on metals. J. Chem. Phys. 1978, 69, 4159-4161. [CrossRef]

6. Hering, K.; Cialla, D.; Ackermann, K. SERS: A versatile tool in chemical and biochemical diagnostics. Anal. Bioanal. Chemi. 2007, 390, 113-124. [CrossRef]

7. Ramón, A.A.-P.; Luis, M.L.-M. SERS Detection of Small Inorganic Molecules and Ions. Angew. Chem. Int. Ed. Engl. 2012, 51, 11214-11223.

8. Zeng, Y.; Koo, K.M.; Trau, M.; Shen, A.G.; Hu, J.M. Watching SERS glow for multiplex biomolecular analysis in the clinic: A review. Appl. Mater. Today 2019, 15, 431-444.

9. Kleinman, S.L.; Frontiera, R.R.; Henry, A.I.; Dieringer, J.A.; Duyne, R.P.V. Creating, characterizing, and controlling chemistry with SERS hot spots. Phys. Chem. Chem. Phys. 2012, 15, 21-36. [CrossRef]

10. Tian, Z.Q.; Ren, B.; Wu, D.Y. Surface-Enhanced Raman Scattering: From Noble to Transition Metals and from Rough Surfaces to Ordered Nanostructures. J. Phys. Chem. B 2002, 106, 9463-9483. [CrossRef]

11. Lin, X.-M.; Cui, Y.; Xu, Y.-H.; Ren, B.; Tian, Z.-Q. Surface-enhanced Raman spectroscopy: Substrate-related issues. Anal. Bioanal. Chem. 2009, 394, 1729-1745. [CrossRef] [PubMed]

12. Lombardi, J.R.; Birke, R.L. Time-dependent picture of the charge-transfer contributions to surface enhanced Raman spectroscopy. J. Chem. Phys. 2007, 126, 175-9201. [CrossRef] [PubMed]

13. Musumeci, A.; Gosztola, D.; Schiller, T.; Dimitrijevic, N.M.; Mujica, V.; Martin, D.; Rajh, T. SERS of Semiconducting Nanoparticles ( $\mathrm{TiO}_{2}$ Hybrid Composites). J. Am. Chem. Soc. 2009, 131, 6040-6041. [CrossRef]

14. Persson, B.N.J.; Zhao, K.; Zhang, Z. Chemical contribution to surface-enhanced Raman scattering. Phys. Rev. Lett. 2006, 96, 207401.1-207401.4. [CrossRef]

15. Zhang, B.; Wang, H.; Lu, L.; Ai, K.; Zhang, G.; Cheng, X. Large-Area Silver-Coated Silicon Nanowire Arrays for Molecular Sensing Using Surface-Enhanced Raman Spectroscopy. Adv. Funct. Mater. 2008, 18, 2348-2355. [CrossRef] 
16. Cheng, C.; Yan, B.; She, M.W.; Li, X.; Hong, J.F. Fabrication and SERS Performance of Silver-Nanoparticle-Decorated Si/ZnO Nanotrees in Ordered Arrays. ACS Appl. Mater. Interfaces 2010, 2, 1824-1828.

17. Hwang, J.S.; Chen, K.Y.; Hong, S.J.; Chen, S.W.; Syu, W.S.; Kuo, C.W.; Syu, W.Y.; Lin, T.Y.; Chiang, H.P.; Chattopadhyay, S. The preparation of silver nanoparticle decorated silica nanowires on fused quartz as reusable versatile nanostructured surfaceenhanced Raman scattering substrates. Nanotechnology 2010, 21, 025502. [CrossRef]

18. Wang, Y.; Ruan, W.; Zhang, J.; Yang, B.; Xu, W.; Zhao, B.; Lombardi, J.R. Direct observation of surface-enhanced Raman scattering inZnO nanocrystals. J. Raman Spectrosc. 2009, 8, 1072-1077. [CrossRef]

19. Sun, Z.; Bing, Z.; Lombardi, J.R. ZnO nanoparticle size-dependent excitation of surface Raman signal from adsorbed molecules: Observation of a charge-transfer resonance. Appl. Phys. Lett. 2007, 91, 7393. [CrossRef]

20. Lai, Y.-C.; Ho, H.-C.; Shih, B.-W.; Tsai, F.-Y.; Hsueh, C.-H. High performance and reusable SERS substrates using Ag/ZnO heterostructure on periodic silicon nanotube substrate. Appl. Surf. Sci. 2018, 439, 852-858. [CrossRef]

21. Liu, Y.; Xu, C.; Lu, J.; Zhu, Z.; Zhu, Q.; Manohari, A.G.; Shi, Z. Template-free synthesis of porous ZnO/Ag microspheres as recyclable and ultra-sensitive SERS substrates. Appl. Surf. Sci. 2018, 427, 830-836. [CrossRef]

22. Chen, P.; Gu, L.; Xue, X.; Song, Y.; Zhu, L.; Cao, X. Facile synthesis of highly uniformZnO multipods as the supports of Au and Ag nanoparticles. Mater. Chem. Phys. 2010, 122, 41-48. [CrossRef]

23. He, X.; Yue, C.; Zang, Y.; Yin, J.; Sun, S.; Li, J.; Kang, J. Multi-hot spot configuration on urchin-like Ag nanoparticle/ZnO hollow nanosphere arrays for highly sensitive SERS. J. Mater. Chem. A 2013, 1, 15010-15015. [CrossRef]

24. Xie, Y.; Yang, S.; Mao, Z.; Li, P.; Zhao, C.; Cohick, Z.; Huang, P.-H.; Huang, T.J. In Situ Fabrication of 3D Ag@ZnO Nanostructures for Microfluidic Surface-Enhanced Raman Scattering Systems. ACS Nano 2014, 8, 12175-12184. [CrossRef]

25. Xu, F.; Zhang, Y.; Sun, Y.; Shi, Y.; Wen, Z.; Li, Z. Silver Nanoparticles Coated Zinc Oxide Nanorods Array as Superhydrophobic Substrate for the Amplified SERS Effect. J. Phys. Chem. C 2011, 115, 9977-9983. [CrossRef]

26. Yin, J.; Zang, Y.; Yue, C.; Wu, Z.; Wu, S.; Li, J.; Wu, Z. Ag nanoparticle/ZnO hollow nanosphere arrays: Large scale synthesis and surface plasmon resonance effect induced Raman scattering enhancement. J. Mater. Chem. 2012, 22, 7902-7909. [CrossRef]

27. Greene, L.E.; Law, M.; Tan, D.H.; Montano, M.; Goldberger, J.; Somorjai, G.; Yang, P. General route to vertical ZnO nanowire arrays using textured $\mathrm{ZnO}$ seeds. Nano Lett. 2005, 5, 1231-1236.

28. Ren, C.; Yang, B.; Wu, M.; Xu, J.; Fu, Z.; Guo, Y.L.; Zhao, Y.; Zhu, C. Synthesis of Ag/ZnO nanorods array with enhanced photocatalytic performance. J. Hazard. Mater. 2010, 182, 123-129. [CrossRef]

29. Yu, J.; Yu, X. Hydrothermal Synthesis and Photocatalytic Activity of Zinc Oxide Hollow Spheres. Environ. Sci. Technol. 2008, 42, 4902. [CrossRef]

30. Liang, Y.; Na, G.; Li, L.; Li, R.; Gan, S. Facile synthesis of Ag/ZnO micro-flower and improved the ultraviolet and visible light photocatalytic activity. New J. Chem. 2016, 40, 1587-1594. [CrossRef]

31. Liu, H.; Hu, Y.; Zhang, Z.; Liu, X.; Jia, H.; Xu, B. Synthesis of spherical Ag/ZnO heterostructural composites with excellent photocatalytic activity under visible light and UV irradiation. Appl. Surf. Sci. 2015, 355, 644-652. [CrossRef]

32. Zhao, L.B.; Huang, Y.F.; Liu, X.M.; Jason, R.; Anema, R.B.; Tian, Z.Q. A DFT study on photoinduced surface catalytic coupling reactions on nanostructured silver: Selective formation of azobenzene derivatives from para-substituted nitrobenzene and aniline. Phys. Chem. Chem. Phys. 2012, 14, 12919. [CrossRef] [PubMed]

33. Zhou, X.D.; Xiao, X.H.; Xu, J.X.; Cai, G.X.; Ren, F.; Jiang, C.Z. Mechanism of the enhancement and quenching of ZnO photoluminescence by ZnO-Ag coupling. EuroPhys. Lett. Assoc. 2011, 93, 57009. [CrossRef] 